\title{
Hybrid Taguchi-Objective Function optimization approach for automatic cave bird detection from terrestrial laser scanning intensity image
}

\author{
Mohammed O. Idrees and Biswajeet Pradhan* \\ ${ }^{1}$ Department of Civil Engineering, Geospatial Information Science Research Center (GISRC), Faculty of Engineering, University Putra Malaysia, \\ 43400 UPM, Serdang, Selangor Darul Ehsan, Malaysia
}

\begin{abstract}
This paper proposes an optimized Taguchi-objective function segmentation-based image analysis to detect bird nests in a cave from high resolution terrestrial laser scanning intensity images. First, the Taguchi orthogonal array was used to design 25 experiments with three segmentation parameters: scale, shape, and compactness, each having five variable factor levels. Then, a plateau objective function was computed for each experiment using their respective level combinations. A merger of the factor level combination in the orthogonal array and the computed plateau objective function values was used to generate main effects and interaction plots for signal-to-noise ratios, which provided a measure of robustness for scale, shape, and compactness factors. The optimized parameters were used in the segmentation process in eCognition. The image object was then classified into nest and cave-wall on the basis of laser return intensity and area index using knowledge-based rule sets, and the detection accuracy was evaluated. The result produced area under ROC curve of 0.93 with $\mathrm{P}<0.0001$ at $95 \%$ confidence level. This indicates that the proposed method is effective for distinguishing birds from cave-wall with high precision. The classification result was transferred to ArcGIS where the detected nests were counted after post-classification editing. A total number of 25,959 nests were counted from the seven scan scenes used. This shows that the fusion of Taguchi and objective function is indeed an effective method to determine optimal segmentation parameters to group image objects as small as birds within a segment. Moreover, the use of segments' spectral intensity value and area index increased classification accuracy significantly. Further, the method was tested for reliability using six additional images. The test of heterogeneity using Cochran's $Q$ and Inconsistency tests produced a $\mathrm{P}$ value of 0.384 and $\mathrm{I}^{2}$ value of $5.10 \%$ at $95 \%$ confidence interval, respectively. This shows that the method is consistent with non-significant difference among the trials.
\end{abstract}

Keywords: Biospeleology, remote sensing, optimization, Gomantong, feature extraction, ecology, terrestrial laser scanning

Received 16 March 2016; Revised 22 October 2016; Accepted 22 October 2016

Citation: Idrees M.O. and Pradhan B., 2016. Hybrid Taguchi-Objective Function optimization approach for automatic cave bird detection from terrestrial laser scanning intensity image. International Journal of Speleology, 45 (3), 289-301. Tampa, FL (USA) ISSN 0392-6672

http://dx.doi.org/10.5038/1827-806X.45.3.1988

\section{INTRODUCTION}

Until lately, ecological research, especially species population census of the inhabitants of caves, has been largely stalled due to perpetual darkness, inaccessibility, and harsh environmental conditions of this unconventional ecosphere (Idrees \& Pradhan, 2016). Gomantong is one of the caves in north Borneo Island with large population of Black and White Nest swiftlet birds (Aerodramus maximus and Aerodramus fuciphagus) and wrinkle-lipped bats (Chaerephon plicata) sharing their dark home (Chasen, 1931). Although the bats and birds rarely intermingle freely, they may roost a meter or few away from each other. The cave is constantly alive with swiftlet birds, bats, and other smaller creatures such as rats, insects, and other invertebrates. Bat and, to some extent, swiftlet droppings (guano) support the cave ecology and sustain the predator-prey relationship within the micro eco-climate (Abdullah et al., 2007; Price, 2014). Economically, the high commercial value of edible bird nests which are made entirely or partly of glutinous saliva containing soluble glyco-proteines and cellular elements has attracted pivotal socioeconomic attention of both the indigenous people and the nation for centuries. Furthermore, the cave 
is a popular destination that receives a large number of both local and foreign tourists that stream into experience the thrilling swiftlet birds' nest harvesting, astounding bat swarm, and the cave powerhouse, guano (Price, 2007; Kingston, 2010). In spite of the centennial interaction of people with the cave and the apparent threat posed by incessant harvesting, it has not been possible to keep track of the actual number of bats/swiftlets birds in the cave until now due to absence of a practical counting method.

Interestingly, however, the growing use of high resolution terrestrial laser scanning (TLS) within caves has recently triggered a new perspective in biospeleology, particularly roosting bats and birds. This field of enquiry pioneered by Azmy et al. (2012) and McFarlane et al. (2015) demonstrates the potentiality of TLS datasets for population surveys as well as understanding the relationship between roosting and the cave morphology. The methods adopted by the researchers are inventive; nonetheless, they have their own limitations. For example, the strength of intensity TLS images lies in the reflectance of the laser pulse which is a function of the reflective ability and properties of the target surface (Remondino, 2003; Haddad, 2011). It is, therefore, unlikely that rocks with different compositional elements will always exhibit uniform reflectance that will constantly produce a distinctively bright cave background. In that case, using intensity value alone as the basis to detect objects as performed by Azmy et al. (2012) will certainly lead to conflicting representations. Also, the method employed by the latter researchers require full resolution scans (McFarlane et al., 2015). Data collection at full resolution is practically time consuming and costly. Furthermore, processing the resulting volume of point cloud is computationally intensive, thus, limiting the application of the method to relatively small areas. In the phase of rising concern for ecologically endangered species, this paper demonstrates that remote sensing approaches will facilitate quantitative spatial econometrics of valuable tropical caves using laser return intensity images.

Advances in computer vision and artificial intelligence have made object-based image analysis (OBIA) a widely accepted technique in the field of remote sensing for object recognition, scene classification, and information retrieval (Martha et al, 2011; Cheng et al., 2013). A number of applications have benefitted from this method (Blaschke, 2010; Anders et al., 2011; Lahousse et al., 2011; Blaschke et al., 2014). In OBIA, unlike pixel-based image analysis, feature classification employs a knowledge-driven approach by exploring spectral information (e.g., color, intensity value), spatial properties (e.g., shape, size), together with associated textural and contextual primitives to represent objects in the scene in a way that best depicts the imaged reality.

Segmentation is the foundation and first major step in image object classification in object-oriented image analysis. The widely used region-growing segmentation technique partitions the image into homogeneous contiguous regions that enclose identical pixels as objects within each segment based on the assumption that an image pixel most likely belongs to the same object as its neighboring pixels (Moosavi et al., 2014). The region-growing process identifies candidate pixels as building blocks for the initial segments and, iteratively, the pixels are amplified with neighboring pixels that satisfy user-supplied homogeneity criteria. In fact, the image classification accuracy is directly controlled by the quality of the segments. And the quality of segmentation itself is controlled by the fitness of the defined parameters (Martha et al., 2011). In eCognition (eCognition9.0, 2014), segmentation quality depends on selection of suitable values for scale, shape, and compactness parameter settings (Tumuhairwe, 2011; Kurtz et al., 2014). The scale factor determines the size of the thematic layer of segments that is composed of a group of homogeneous pixels. On the other hand, shape and compactness factors, which are associated with color density and smoothness, specify how much spectral information should be aggregated to build segments. These parameters synchronously determine the sensitivity of feature detection and classification accuracy.

Until Espindola et al. (2006) proposed the objective function to select appropriate parameters that can produce the best quality segmentation based on intra-segment homogeneity and inter-segment reparability, selection of segmentation parameters have conventionally been achieved by trial-and-error basis. Even so, most applications that employed this method (e.g., Gao et al., 2011; Martha et al., 2011; Moosavi et al., 2014, Pradhan et al., 2015) have consistently emphasized on the scale parameter alone while other factors are kept constant, despite the fact that they collectively contribute to the overall segment quality.

In this paper, the statistical Taguchi (Chou et al., 2009) and objective function (Espindola et al., 2006) robust methods were combined in a single processing flow to optimize segmentation parameters for the detection of edible white-nests in Simud Putih (the Gomantong's upper level cave). The situation is even much more complex involving objects such as birds of sub-centimeter area scale, located closely to one another in a dark cave environment. Therefore, merging of the statistical and spatial optimization process creates intrinsic sensitivity to the image pixels and their spatial relationship and the strength of these properties is utilized to obtain the desired quality. The principal motivation for this hybrid approach is the awareness that segmentation is not affected only by controllable factors but also by factors that are difficult to control (i.e. clustering of pixels belonging to the same object).

\section{STUDY AREA AND DATA}

Gomantong Cave is situated in one of the towerlike limestone outcrops in Sabah, North Boneo. The limestone hill sits within the 3000 hectares Gomantong Forest Reserve (118 04'E, $\left.5^{\circ} 32^{\prime} \mathrm{N}\right)$, some 34 kilometers south of Sandakan and about 34.1 kilometers east of the state capital, Kota Kinabatangan. To the south of the hill is the Lower Kinabatangan River that 
flows in the northeast direction into the Sulu Sea (Fig. 1). The profile of the hill from the peak is a tower-like outcrop where the limestone folds to form a syncline of near-vertical joints. Around the cave, the limestone dips between $20-30^{\circ}$ to the north-west which provides entrance along one of the major faults (Lundberg \& McFarlane, 2012). The hill is penetrated by complex cave systems that consist of two major halls, one above the other. The more accessible lower cave, Simud Hitam (or Black Cave), opens to the base of the hill close to and level with the bank of a small stream (Fig. 1) while the entrance to upper cave, Simud Putih (or White Cave), is located about $85 \mathrm{~m}$ above the floor of the entrance to the lower cave (Abdullah et al., 2005; McFarlane et al., 2013). Gomantong Cave, like every other cave, is dark and humid, providing an excellent microclimate habitat that is suitable for swiftlet birds and bats to live as far back as 600 years ago (Abdullah et al., 2005; Kingston, 2010).

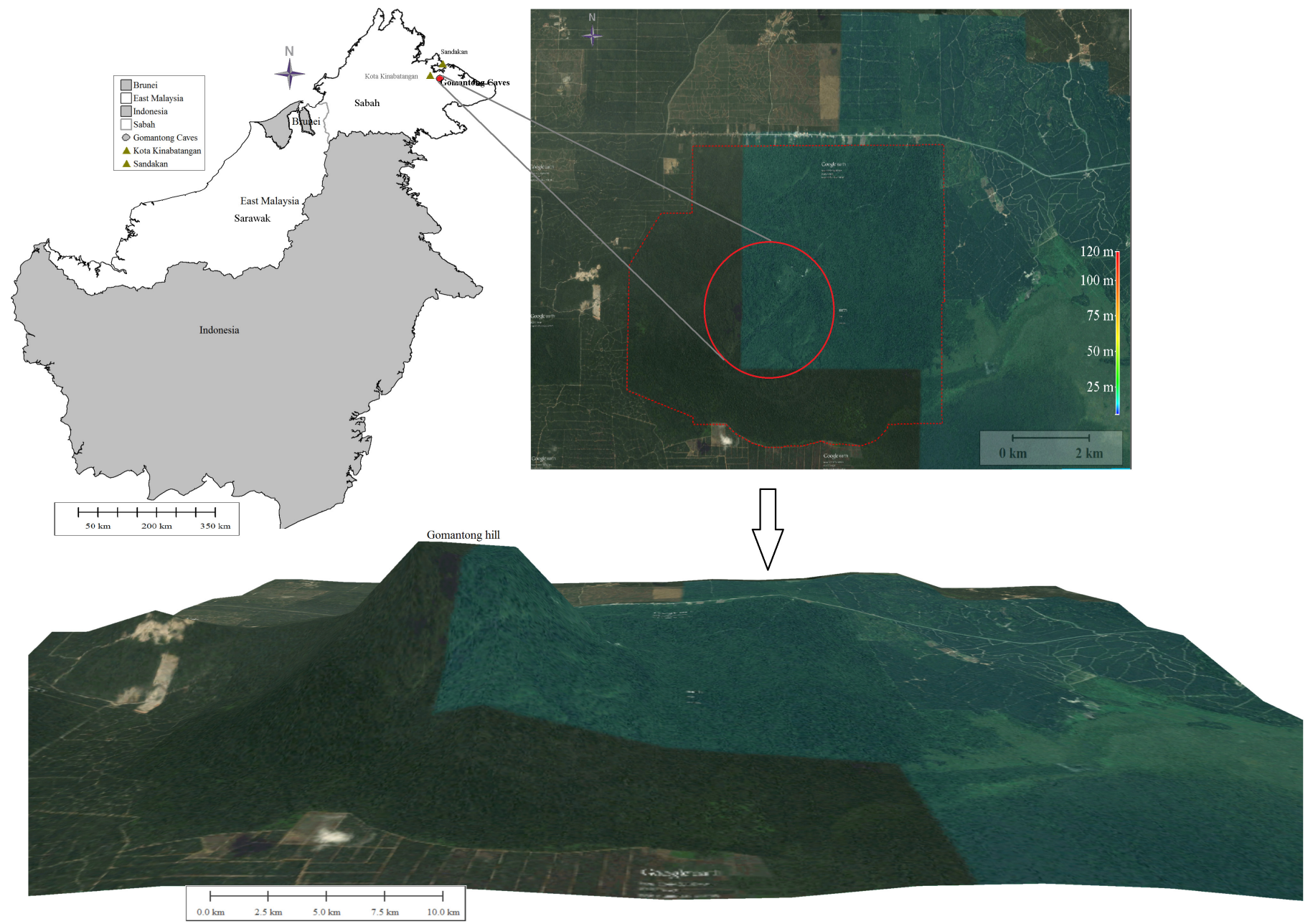

Fig. 1. Map of Borneo Island: The location of Gomantong caves is shown with a red dot north of the Island (top-left) corresponding to the red circle within the map of the Forest Reserve (upper-right); 3D model generated by draping high resolution GoogleMap image on 30 second resolution SRTM digital elevation model showing the Gomantong Hill (bottom).

\section{Data used}

The entire Gomantong cave system was scanned in July, 2014, using FARO Focus3Dx130 instrument at $1 / 4$ resolution mode $(\approx 244,000$ points/second $)$ to generate a point cloud spacing of $12.5 \pm 2 \mathrm{~mm}$ ranging error and intensity image. $1 / 4$ scan resolution mode increases the efficiency of the scan because it balances the speed of data acquisition and quality of the scan. Furthermore, the unique small weight $(\sim 5$ $\mathrm{kg}$ ), high distance accuracy and ease of use (Idrees and Pradhan, 2016) makes Focus3D a suitable choice for scanning the Gomantong Cave.

The scan data were pre-processed in FAROScene v.5.5.0 software package (http://www2.faro.com/ downloads/training/Software). Since points scanned at each setup are stored in different scanner Cartesian coordinates, the initial task was to align individual scans into one point cloud referenced to a single Cartesian coordinate system. For high quality registration, automatic target-based point correspondence which employs the iterative closest point (ICP) algorithm (Besl and McKay, 1992) was used. The system automatically detects at least three points from the artificial targets strategically placed to be visible in successive adjacent scans to compute accurate transformation parameters. The quality of registration was further improved by activating auxiliary sensors (inclinometer, compass and altimeter) to speed-up the process of individual scan correlation. Thereafter, the point cloud was filtered using a distance threshold of $200 \mathrm{~m}$ to automatically eliminate isolated points considered as noise whereas points that belong to features outside the cave were manually deleted. Finally, 99 intensity images of the registered scans were exported, from which seven were randomly selected for the development and validation of the method. 


\section{METHODOLOGY}

The research was executed through a step-by-step workflow presented in Fig. 2. A brief description of the data processing and analysis employed follows.

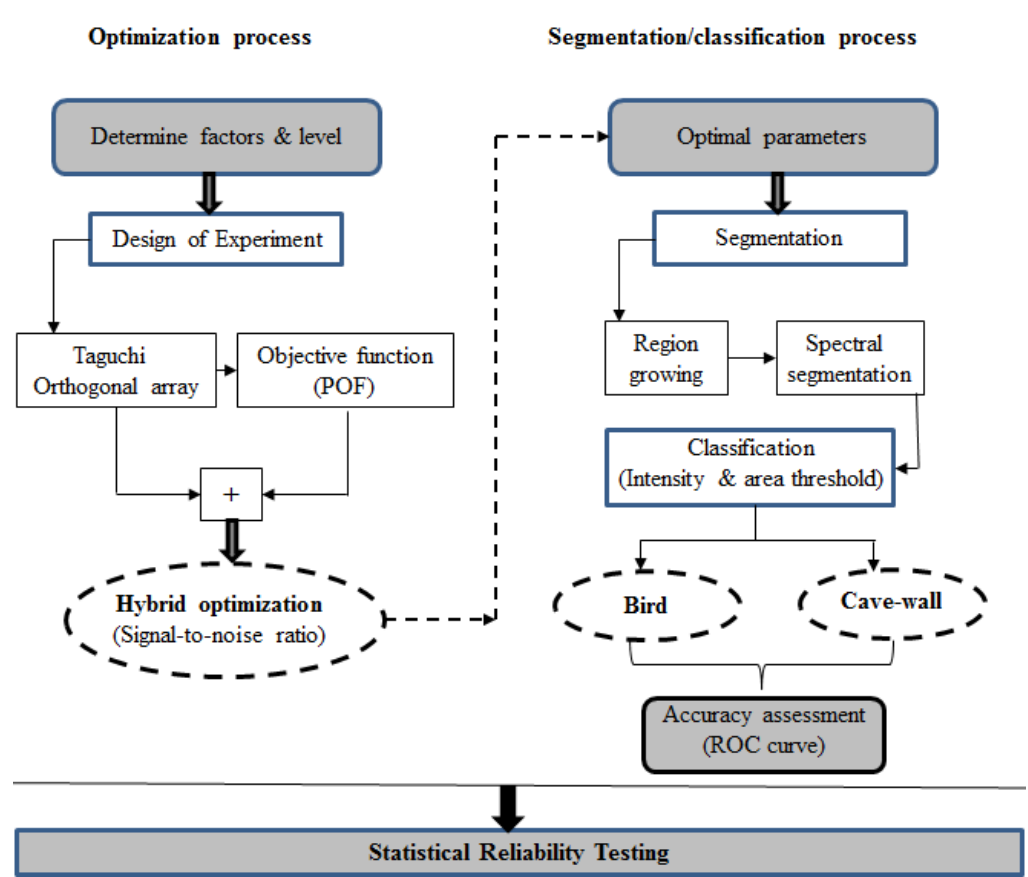

Fig. 2. Methodological workflow.

\section{Optimizing segmentation}

\section{Taguchi method}

Dr. Genichi Taguchi developed statistical methods to reduce variation in factors that undermine consistency in a product or process through a robust design of experiments to improve the quality of manufactured goods (Rao et al., 2008; Chou et al., 2009; Thaduri et al., 2013). The method determines optimum parameters by manipulating variable factor levels, and estimates their effects on the response mean and variance of the process performance characteristics. In Taguchi methods, the experiment is designed using an orthogonal array such that within each pair of columns representing independent variables, each combination of levels occurs an equal number of times (Rao et al., 2008; Pradhan et al., 2015). By doing so, the effects of all the factors can be balanced and, thus, give a relative value that represents the effects of a level compared with other levels of the same factor. The advantage of Taguchi's orthogonal array design of experiment (DOE) is that it considerably minimizes the number of experiments by employing fractional factorial design (Chou et al., 2009). Taguchi's Signal-to-Noise ratios, which are log functions of desired output, provide a measure of optimization through constraints and with variables that need to be minimized or maximized. Analysis of the combined experimental result and optimization using $\mathrm{S} / \mathrm{N}$ ratio produce the best statistical prediction of optimum process (or segmentation) parameters.

\section{Objective function}

Even though correct selection of segmentation parameters is important, and the power of Taguchi methods optimize this process, it does not automatically result in high-precision target detection because the segmentation process depends not only on these parameters, butalso on correct grouping of image spectral relative their spatial arrangement (autocorrelation). As mentioned earlier, the objective function exploits the combination of spatial autocorrelation and variance indices to select the ideal parameters to evaluate segmentation quality (Espindola et al., 2006; Gao et al., 2011). Spatial autocorrelation indicates the level of distinctiveness between regions (heterogeneity) while the variance indicator expresses the uniqueness of the pixels in individual segments. So, segmentation is of good quality when intrasegment homogeneity and intersegment heterogeneity conditions are strictly maximized. Fundamentally, experiments with the highest Plateau objective function (POF) value indicate best performance and, therefore, a mark of strength of the quality. This can be true where only a single variable factor like scale is considered to affect the result (Espindola et al., 2006; Gao et al., 2011). But where multiple variable factors influence the result, the use of objective function may not likely yield the best result.

Operationally, the objective function $(\mathrm{F})$, fuses the within-segment variance (v) measure and the between-segment autocorrelation Moran's I index (I) (Espindola et al., 2006) as given by:

$$
F(v, I)=F(v)+F(I)
$$

where $F(v)$ and $F(I)$ are normalization functions as

$$
F(x)=\frac{X_{\max }-X_{i}}{X_{\max }-X_{\min }}
$$

The first element of objective function, mean and variance of the segments was computed using the laser intensity value of sampled regions.

$$
v=\frac{\sum_{i=1}^{n} a_{i} v_{i}}{\sum_{i=1}^{n} a_{i}}
$$

Where $a_{i}$ and $v_{i}$ are the area and intrasegment variance the respective segment $i$. And the second component, Moran's I index expressed as

$$
I=\frac{n}{S_{0}} * \frac{\sum_{i=1}^{n} \sum_{j=1} w_{i, j} z_{i} z_{j}}{\sum_{i=1}^{n} z_{i}^{2}}
$$

where $z_{i}$ is the deviation of the brightness value of the object $i$ from its mean $\left(x_{i}-\bar{X}\right), w_{i, j}$ is the spatial weight between objects $i$ and $j$, which is 1 for adjacent regions or 0 otherwise, $n$ is the total number of objects, and $S_{0}$ is the aggregate of all spatial weights.

$$
S_{0}=\sum_{i=1}^{n} \sum_{j=1}^{n} w_{i, j}
$$


Robust Hybrid optimization strategy

The basis of this hybrid robust design is the awareness that the quality of the objective function is still subject to the quality of the scale, shape, and compactness parameter variation. And achieving this by trial-and-error approach can introduce errors that may affect the quality of the resulting optimized parameter (Pradhan et al., 2015). This necessitates the idea of integrating statistical (Taguchi method) and spatial (objective function) optimization methods in a single processing step to model optimal parameters that guarantee best quality segments. Sensitivity of segmentation to pixel neighborhood as the bases for feature grouping and the role of scale, shape, and compactness parameters on the quality of segmentation and classification are the core fundamentals of this approach. To accomplish the hybrid optimization strategy, the following core steps were implemented.

a) Evaluate process objectives to understand variables that control the desired result.

b) Determine the parameters and the range of values that directly influence the quality of the process.

c) Based on the number of parameters and variable level, design experiments to determine number runs.

d) Use the values of the parameter level combinations to compute the POF for each experiment.

e) Combine results of steps $\mathrm{c}$ and $\mathrm{d}$ to analyze and predict the optimum segmentation parameters using Taguchi's $\mathrm{S} / \mathrm{N}$ ratio.

f) Implementation - the final follow-up experiment performed to verify the result.

Unlike the standard full factorial design, the orthogonal array examines pairs of combinations with each factor level weighted equally so that each factor is assessed independently. The advantage of the Taguchi method is that it significantly reduces the number of experiments and minimizes cost (Moosavi et al., 2014). The initial requirement to use the orthogonal arrays is to identify the number of factors affecting the process and the levels of variation. For region-growing segmentation in eCognition, only three factors; scale, shape, and compactness that control segmentation were used with five varying conditioning levels (Table 1). After careful consideration of the size of the cave birds with some tests, it was discovered that the effective scale range should be between 10 and 30 to avoid over- and under-segmentation. Again, since shape and compactness factors depend on color density and smoothness, same values were assigned to both factors at each level.

Unlike in standard factorial designs that yield $5^{3}$ (125) number of experiments for this combination, the proposed Taguchi orthogonal array experimental

Table 1. Segmentation factors and their levels used for optimization.

\begin{tabular}{|l|c|c|c|c|c|}
\cline { 2 - 6 } \multicolumn{1}{c|}{} & \multicolumn{5}{c|}{ Level } \\
\hline Parameters & 1 & 2 & 3 & 4 & 5 \\
\hline Scale & 10 & 15 & 20 & 25 & 30 \\
\hline Shape & 0.05 & 0.2 & 0.4 & 0.7 & 0.9 \\
\hline Compactness & 0.05 & 0.2 & 0.4 & 0.7 & 0.9 \\
\hline
\end{tabular}

design table provides only 25. This means that only 25 experiments (one-fourth of the full factorial design) is capable of producing equally weighted factor levels across the design. The Taguchi orthogonal array design was implemented in Minitab v.17 statistical software (Minitab17, 2016). Based on parameter level combinations in the orthogonal arrays, 25 segmentation tests were executed and the corresponding POF were computer for each test. For consistency, the experimental segments were extracted from the subset image with fair representation of birds and cave wall. Thereafter, analysis of the signalto-noise $(\mathrm{S} / \mathrm{N})$ ratio was used to model the optimal segmentation parameters. To arrive at this, the effect each variable has on the output was determined by calculating the $\mathrm{S} / \mathrm{N}$ ratio for each experiment conducted using the mean value, $y_{i}$ and $s_{i}$ variance expressed as

$$
S N_{i}=10 \log \frac{\overline{y_{i}^{2}}}{S_{i}^{2}}
$$

where

$$
\begin{gathered}
\overline{y_{i}}=\frac{1}{N_{i}} \sum_{u=1}^{N_{i}} y_{i, u} \\
s_{i}^{2}=\frac{1}{N_{i}-1} \sum_{u=1}^{N_{i}}\left(y_{i, u}-\overline{y_{i}}\right)
\end{gathered}
$$

In equations (7) and (8), $i$ is the experiment number, $u$ is the trial number, and $N_{i}$ is the number of trials for experiment $i$. Our objective is to maximize the performance characteristic, so, the 'higher is better' option was used for the calculation of the $\mathrm{S} / \mathrm{N}$ ratio based on the following equation:

$$
S N_{i}=-\log 10\left[\frac{1}{N_{i}} \sum_{u=1}^{N_{i}} \frac{1}{y_{u}^{2}}\right]
$$

After that the $\mathrm{S} / \mathrm{N}$ ratio has been computed for each experiment, the average of the $\mathrm{S} / \mathrm{N}$ value for each factor and level is derived and the result is exported as a table and a graph.

\section{Segmentation and classification processes Test}

The widely used multiresolution segmentation algorithm was employed on a subset image to test the efficiency of the proposed method and the resulting image object was classified to extract bird nest polygons. The modeled optimal scale, shape, and compactness parameter that maximizes peak plateau was utilized to segment the image using the bottom-up region growing technique (Danneels et al., 2007; Blaschke, 2010). The parameters exhibit an utmost ability to delineate objects as small as the size of a bird (Fig. 3), measuring, at most, about 50 square centimeter in area, a departure from the natural physical surface where features of 
interest occupy large areas at varying spatial scales. Before the classification process, spectral segmentation was performed (Fig. 3B) to further merge contiguous regions of similar physionomy, especially for the rock surface that appears over-segmented due to the scale factor considered for bird detection.
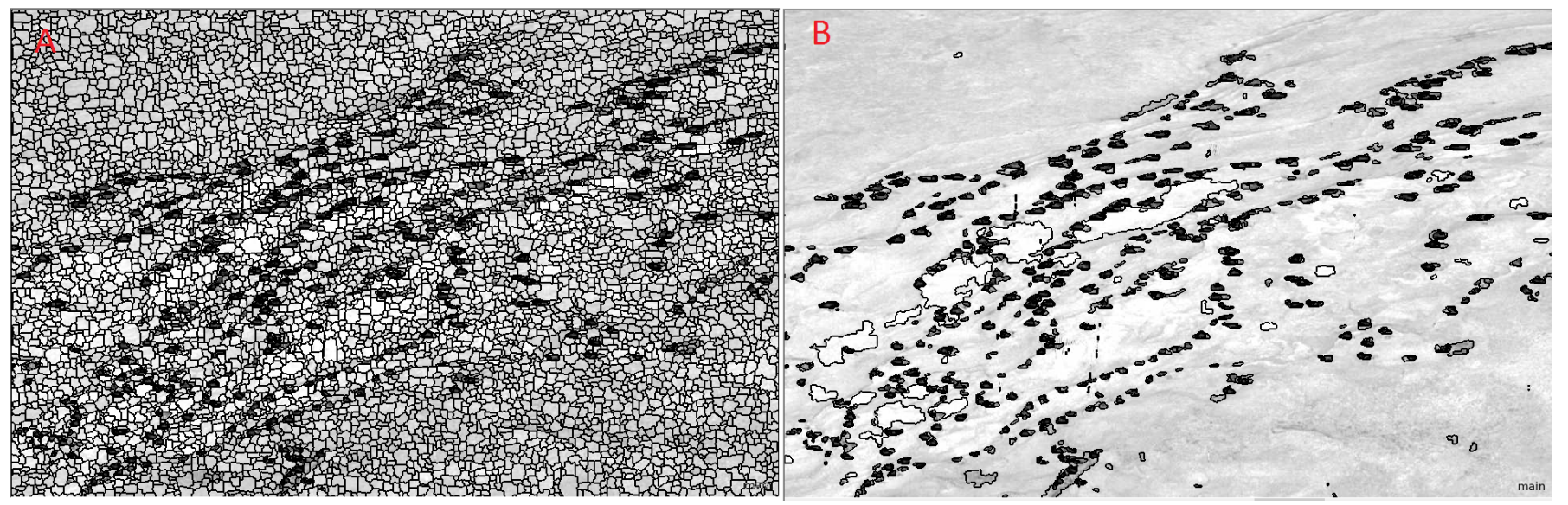

Fig. 3. Segmentation process for (A) multi-resolution and (B) spectral difference.

Feature discrimination was accomplished through a combination of spectral and geometric properties associated with the segments. In the intensity image, nests stand out because the spectral characteristics are darker than the cave wall and the geometric characteristics (shape and size) are quite small (centimeter level). This information was useful for the development of a rule set (a knowledge-based expert system) that was transferred to a process in eCognition to automatically detect and classify the image objects using a combination of segmentation and classification algorithms. From the result, features of interest (bird nests) were extracted. Complete darkness in caves make it impossible to use photographic images to compare the results, therefore, the decision was made to use image section that facilitates direct manual counting of the detected/undetected nests.

\section{Validation}

To empirically proof the effectiveness of the proposed approach, the developed rule-set was tested on the full scan intensity image to concurrently segment and classify the image objects into two feature classes, nests and cave-wall. The data-driven thresholding operation employs both the spectral and geometric characteristics (Gao et al., 2011; Tumuhairwe, 2011) of the diagnostic features for the classification process. A subclass, shadow, was added to cave-wall class to understand how low contrast between cave wall and nest class affects detection. The classified object layers were later transferred to ArcGIS10.2 for further analysis. Prior to feature extraction, the precision of detection was statistically evaluated using a binary classifier, Receiver Operating Characteristic (ROC) curve analysis. Finally, the nest class was extracted, followed by a clean-up exercise to eliminate image objects wrongly detected as bird nest using pixel area thresholding.

\section{Accuracy assessment}

From computer-vision point of view, the task of detecting objects from an image is far from trivial, and may give wrong results if executed imprecisely. Unlike the standard remote sensing image classification of the terrain surface with many land use/cover classes, the physical topography of a cave is substantially made up of rock that forms the wall, and only secondarily bats, birds, reptiles, and occasionally an underground river. So, a binary classification was employed to evaluate the classification results using receiver operating characteristic (ROC) curve (Powers, 2011). ROC is an excellent tool that is increasingly used in machine learning and data mining research of this nature for diagnostic performance evaluation. Again, since the two classes are not symmetric, rather than overall accuracy, the relative proportion of the different types of errors is of interest. Details of the basic ROC analysis can be found in Hanley \& McNeil (1982), Flach et al. (2011), and Powers (2011).

A Supervised learning method was employed by collecting random sample points representing the classes as test data to evaluate the precision of the probabilistic observations. Metz (1978) suggested that meaningful qualitative conclusions can be reached with a total dataset of 100 samples. Here, we used 200 samples: 100 birds; 60 cave-wall features; and 40 shadow areas. The distribution of samples, for cave wall and shadow areas (both of which are considered as the same class) was done to cater for bias in the sensitivity/specificity performance. With the spatial join function in ArcTool box, the sampled test data and the corresponding properties of the feature class layers (the diagnostic data) were retrieved in a single table for use in the statistical MedCalc software (MedCalc16.0, 2016). First, an independent evaluation of the intensity-based classifications was performed. Thereafter, accuracy of the combined spectral and geometric properties-based classification result was examined against the diagnostic data to assess their respective response to detectability using the area under ROC curve indices.

\section{RELIABILITY TESTING}

The consistency test is essential for analyzing the reliability of a method or process. Knowing how consistent the results of different studies are is 
useful for determining the credibility of the method that produced them. For this reason, the method was implemented using six images randomly selected from the cave. The ROC curve analysis of the six trials was processed simultaneously to test the statistical significance of the difference between the areas under ROC curves and to obtain their quantitative results for further analysis. The quantitative outcome from the compared ROC curves was used as input parameters for the reliability test. In this case, decision on whether the method is credible or not was investigated using two measures; i) estimate the overall effects of interest and ii) statistical test for heterogeneity.

\section{Estimating overall effects}

The effect of interest here is the area under ROC curves. A numerical estimate of the overall effects was achieved by taking the weighted average of the estimated effect from the respective study (Petrie et al., 2003). The overall effect is expressed as:

$$
\hat{\theta}=\frac{\sum \hat{\theta}_{i} w_{i}}{\sum w_{i}}
$$

where $\hat{\theta}_{i}$ is the estimated effect and $w_{i}$ the weight of the $i^{\text {th }}$ study. Usually the reciprocals of the standard errors are allocated as weights; thus, smaller standard errors get more weight in the calculation of the pooled effect size. The overall pooled effect is determined quantitatively using the fixed-effects and randomeffects estimation methods. Fixed-effects estimator believes that there is a common true effect in each study which is constant to all the studies; hence, what is reported is an estimate of the magnitude of the common effect. Conversely, the random-effects method assumes that the true effects vary between studies and the estimated effect is the weighted average of all the effects obtained from all the trials (Petrie et al., 2003; Borenstein et al., 2009). But unlike the fixed-effects, the random-effects estimator takes into account both the random variation and the heterogeneity of the standard error across all the trials. As a rule, therefore, results of the two models will be similar if there is no heterogeneity.

\section{Testing for heterogeneity}

Investigating the null hypothesis that all the studies are evaluating a uniform effect of interest is usually verified on a standard scale of the test statistic, Cochran's Q (Petrie et al., 2003; Higgins et al., 2003) computed by taking the sum of squares of the deviation of the individual estimated effect from the overall effect.

$$
Q=\sum w_{i}\left(\hat{\theta}_{i}-\hat{\theta}\right)^{2}
$$

In general, the magnitude of the test statistic is decided on the basis of a $\mathrm{P}$ value which is compared to a chi-square distribution with $\mathrm{k}-1$ degree of freedom. Q test has been widely used for testing heterogeneity; however, it is known to be weak at identifying true heterogeneity among studies and the inability to describe reasonably the extent of intrinsic heterogeneity (Higgins et al., 2003). So, in addition to Q-test, the degree of disagreement in the studies' results was quantified using the inconsistency $\mathrm{I}^{2}$ test (Higgins et al., 2003). $\mathrm{I}^{2}$ is computed using the results obtained from the Cochran's test statistic (Equation 11) except that it is expressed as a percentage of total variation across studies that results from true heterogeneity rather than probability (Higgins et al., 2003); as given in the expression:

$$
I^{2}=100 \% *(Q-d f) / Q
$$

where $Q$ is the Cochran's heterogeneity and $d f$ is the degree of freedom. The advantage of $\mathrm{I}^{2}$ over Q-test is that it is independent on the number of experiments and takes into consideration inherent heterogeneity (Higgins et al., 2003; Borenstein et al., 2009).

\section{RESULTS AND DISCUSSION}

\section{Parameter optimization results}

Table 2 presents the Taguchi orthogonal array and POF values computed based on scale, shape, and compactness level combinations. Minitab conventionally code factor levels as integer, depending on the number of levels. For instance, numbers $1,2 \ldots$ 5 under each factor represents the unit vector (refer to Table 1).

From the table, the highest POF value (1.46) was generated with parameter combinations of experiment 19. According to the logic of objective function, it means that scale, shape, and compactness factors at levels 4, 4, and 2 (i.e., 25, 0.7, and 0.2), respectively

Table 2. L25 orthogonal array and the corresponding POF.

\begin{tabular}{|l|c|c|c|c|}
\hline RUN & SCALE & SHAPE & COMPACTNESS & POF \\
\hline Test-1 & 1 & 1 & 1 & 1.11 \\
\hline Test-2 & 1 & 2 & 2 & 1.09 \\
\hline Test-3 & 1 & 3 & 3 & 1.00 \\
\hline Test-4 & 1 & 4 & 4 & 1.17 \\
\hline Test-5 & 1 & 5 & 5 & 1.26 \\
\hline Test-6 & 2 & 1 & 2 & 0.97 \\
\hline Test-7 & 2 & 2 & 3 & 0.96 \\
\hline Test-8 & 2 & 3 & 4 & 1.03 \\
\hline Test-9 & 2 & 4 & 5 & 1.21 \\
\hline Test-10 & 2 & 5 & 1 & 1.19 \\
\hline Test-11 & 3 & 1 & 3 & 0.89 \\
\hline Test-12 & 3 & 2 & 4 & 0.85 \\
\hline Test-13 & 3 & 3 & 5 & 1.24 \\
\hline Test-14 & 3 & 4 & 1 & 1.11 \\
\hline Test-15 & 3 & 5 & 2 & 0.60 \\
\hline Test-16 & 4 & 1 & 4 & 1.09 \\
\hline Test-17 & 4 & 2 & 5 & 1.11 \\
\hline Test-18 & 4 & 3 & 1 & 0.80 \\
\hline Test-19 & 4 & 4 & 2 & 1.46 \\
\hline Test-20 & 4 & 5 & 3 & 0.51 \\
\hline Test-21 & 5 & 1 & 5 & 0.99 \\
\hline Test-22 & 5 & 2 & 1 & 0.83 \\
\hline Test-23 & 5 & 3 & 2 & 1.02 \\
\hline Test-24 & 5 & 4 & 3 & 1.02 \\
\hline Test-25 & 5 & 5 & & 0.15 \\
\hline
\end{tabular}


will be considered. But a closer look at the table reveals $\mathrm{POF}$ with values close to the highest POF in a pattern that correlates with the analyzed signal-tonoise values. For example, in column for scale factor the POF values for level 1 have closely the same high values. The same trend can be observed in all rows where 4 appeared in the shape column, likewise in all rows with 5 in compactness column. The hybrid strategy simultaneously weighs the orthogonal vectors and $\mathrm{POF}$ to compute the $\mathrm{S} / \mathrm{N}$ ratios. This results in the predictive optimal factor levels that are suitable for segmentation. Table 3 and Fig. 4 show the S/N ratio values and mean effect plots.

Table 3. Response table for signal to noise ratios (larger is better).

\begin{tabular}{|l|c|c|c|}
\hline Level & SCALE & SHAPE & COMPACTNESS \\
\hline 1 & 1.01205 & 0.05714 & -0.02912 \\
\hline 2 & 0.5713 & -0.34412 & -0.11493 \\
\hline 3 & -0.83372 & 0.08019 & -1.40909 \\
\hline 4 & -0.58264 & 1.48495 & -3.13898 \\
\hline 5 & -3.5766 & -4.68778 & 1.2825 \\
\hline Delta & 4.58864 & 6.17274 & 4.42148 \\
\hline Rank & 2 & 1 & 3 \\
\hline
\end{tabular}

In the graph, the factor level is in the $\mathrm{x}$-axis while the mean $\mathrm{S} / \mathrm{N}$ ratio is in the $\mathrm{y}$-axis. The level with highest average $\mathrm{S} / \mathrm{N}$ ratios (Table 3) indicates maximum performance and, ultimately, the one that meets the optimum condition to produce best quality segments. Therefore, the scale, shape, and compactness factors are best at levels 1,4 , and 5 respectively; representing vector combinations of 10, 0.7 and 0.9 (refer to Table 2). Fig. 4 displays this graphically as an indicative of the "Larger is better" option which guarantees maximizing the output values. It can be observed that the new combinations are not just a selection from the experiments based on the POF index, as in the works of Gao et al,(2011), Martha et al. (2011), and Moosavi et al. (2014), but a completely new synergistic combination of factors that guarantees the best mix that satisfies optimally intersegment heterogeneity, intra-segment homogeneity, and segment quality for the target object. Aside optimization, the factors are quantitatively ranked

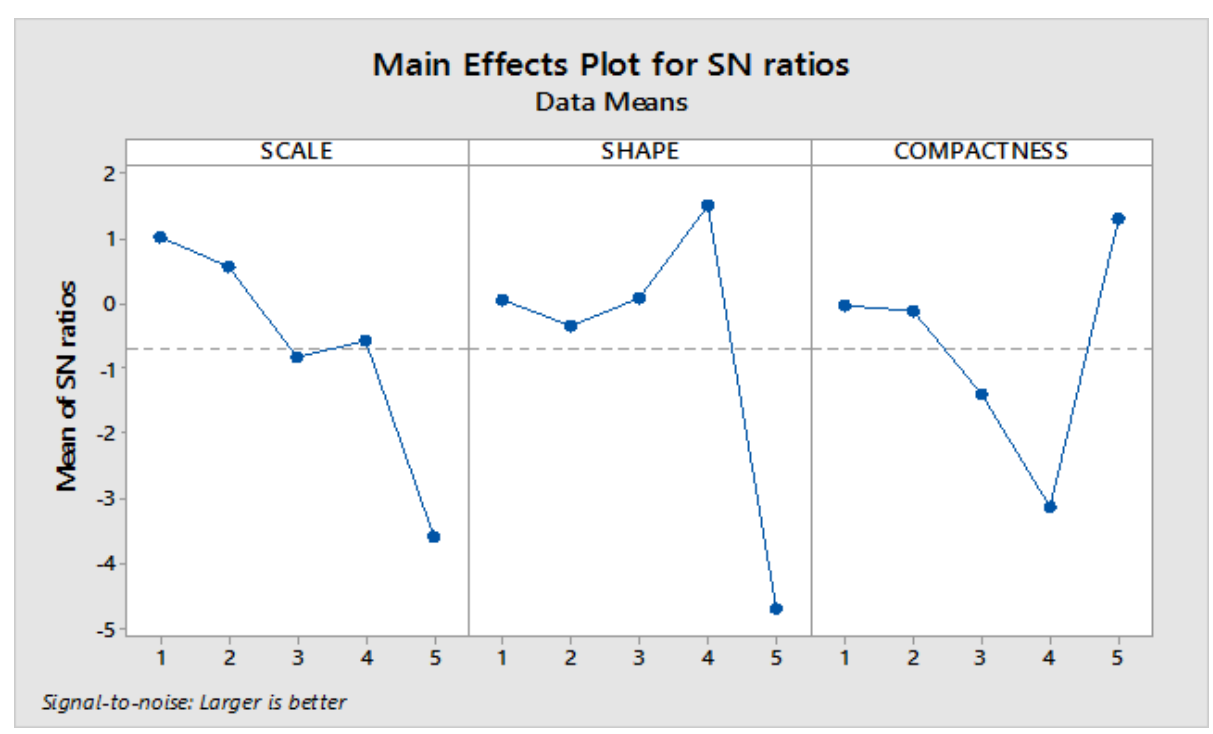

Fig. 4. Mean effects plot for $\mathrm{S} / \mathrm{N}$ ratios (larger is better). according to their level of significance. Here, shape ranks as the best contributor, followed by scale and, lastly, compactness. The ranking further supports our argument that keeping other factors constant aside scale can reduce the quality expected with the objective function.

\section{Classification results}

\section{Test result}

The knowledge-based expert system is a valuable resource for feature extraction. The selected classes were extracted on the basis of the strength of laser intensity and segment area. The method is efficient with nearly 100 percent success in detecting nests. In the test image, a total number of 610 objects were detected as birds (Fig. 5). However, visual observation and counting indicates that the method overapproximated birds by $9 \%$ of the actual number of birds in the image. It efficiently discriminates shadow from rock projections and fractures that share similar intensity value with birds but characteristically differ in shape indices (area, elongation, etc.). An accurate population count was achieved semi-automatically by eliminating instances in which dark crevices on the cave wall are detected as birds using area pixel threshold and manual editing. The actual number of nests detected in the image subset is 556, equivalent to $91 \%$ of the detected polygons.

\section{Validation result}

Figure 6 shows the detected birds from the whole intensity image. It can be observed that the nests are precisely detected in their roosting position, high on the cave ceiling. The result demonstrates that our method can sufficiently detect nests in areas of low contrast caused by dark surface background as much as it does in a highly contrasting background. Spectral ambiguities that may have arisen from low contrast between the cave wall and birds were correctly resolved by taking object geometry into consideration rather than relying solely on intensity values of detection. Furthermore, the sensitivity of the method to measure spatial autocorrelation and variance and to identify and group objects based on their spectral relationship and form using a correct mix of segmentation parameters improves feature detectability.

The general spatial arrangement observed visually was supported using global Moran's I. Positive spatial autocorrelation with Moran's I of 0.47 indicates spatial distribution that is neither randomly distributed nor clustered in agreement with the findings of McFarlane et al. (2015). In addition, the patterns in which swiftlets choose roosting locations show that the cave morphology has a strong influence. This was confirmed through visual and cross-sectional analysis of the 3D point cloud in CloudCompare. It was discovered that roosting 


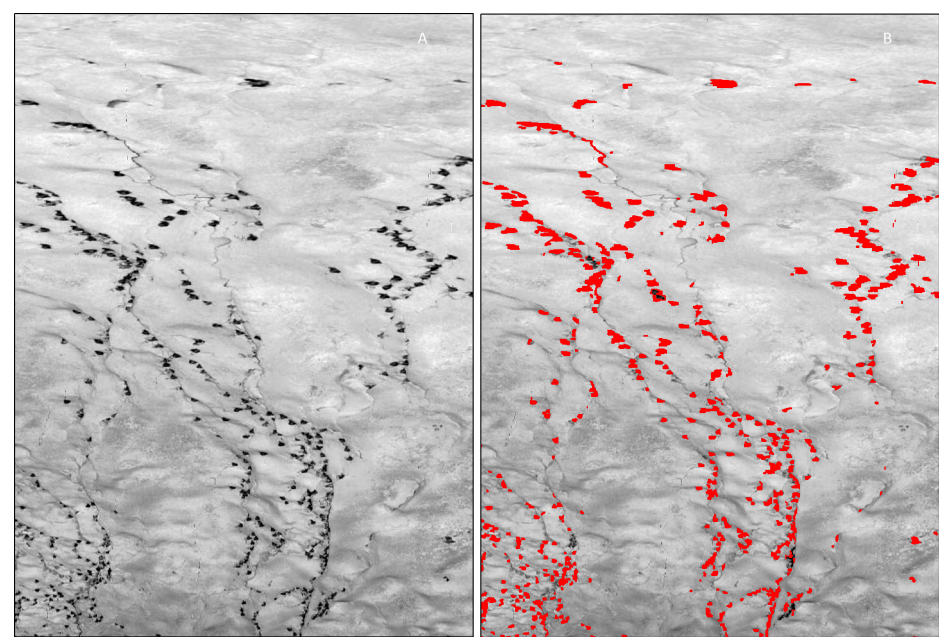

Fig. 5. Laser intensity image subset (A) and detected bird overlay on the image (B).

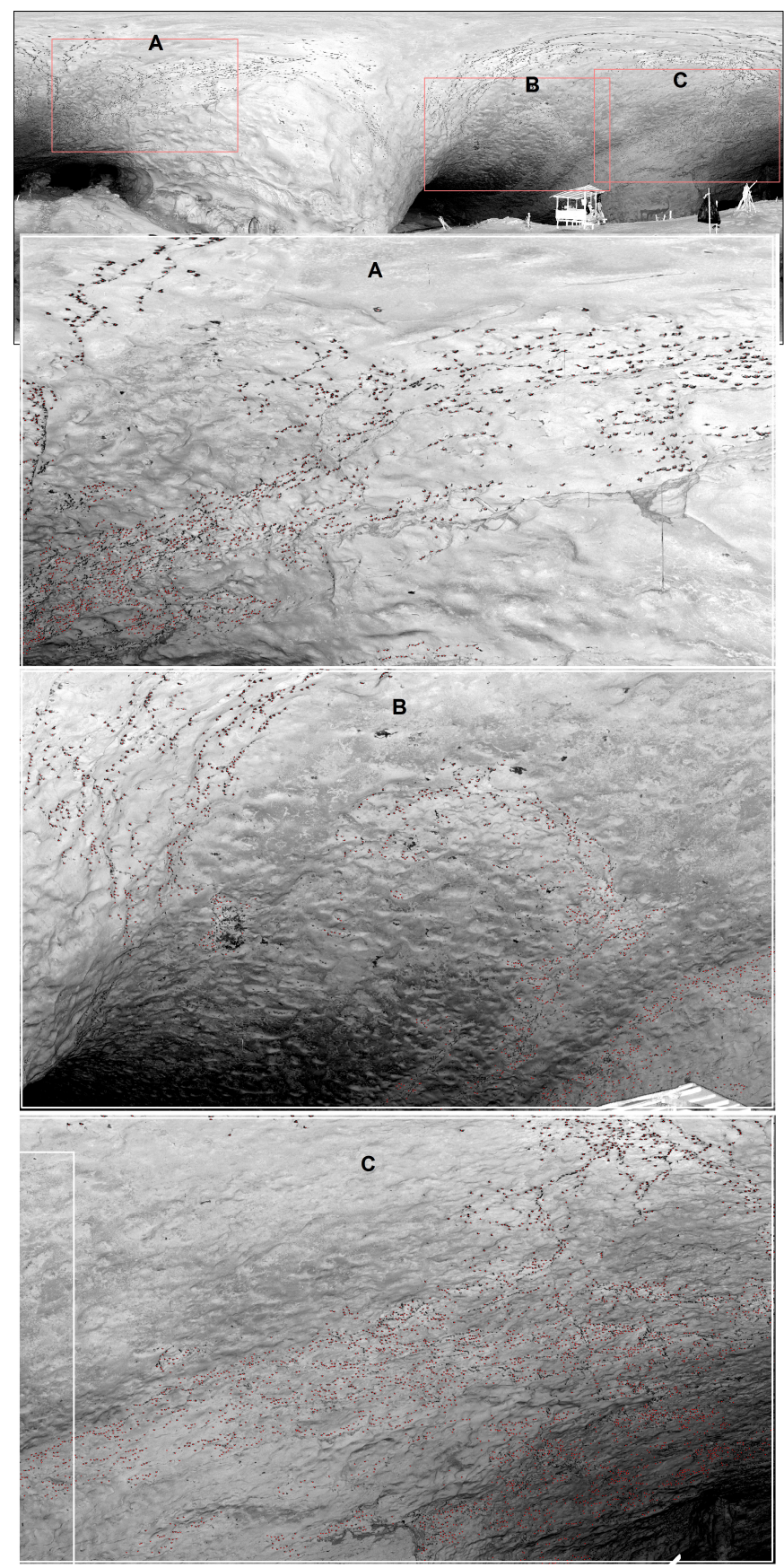

Fig. 6. TLS intensity image scene used for developing and testing the method (Top) with sections of the rectangular boxes A, B, and C showing clearly the detected nests in red dots on the image for the three sections in that order. locations are more concentrated around rock joints, rough and concave-like surfaces with slope varying between gentle and steep slope $\left(3^{\circ}-35^{\circ}\right)$. After cleanup operations, the centroid point of the polygons was generated making a total number of 7,306 nests detected from the single image scene.

\section{Accuracy assessment results}

Results of the classification accuracy assessment are presented in Fig. 7 and Table 4. The graph of sensitivity-specificity plots provide visual and statistical understanding of how well the method is able to discriminate between nests and cave wall. Interactively, the sensitivity measures how good the classification is at picking out segments that are truly bird (otherwise called the true positive), while the specificity indicates ability of the classification to correctly identify non-nest segments (true negative) (Flach et al., 2011). Assessment with brightness value shows that the laser return intensity value is highly sensitive to detecting nests with 94\% sensitivity. However, apparent overlap between bird and cave wall classes cause the curve to intercept the diagonal line (Fig. 7A), supported statistically with a specificity value of $57 \%$. The implication of this is that there is a greater suspicion of the possibility to choose an individual from the negative class as true positive if only the intensity value is used.

Accuracy measurement of the brightness valuebased classification yielded area under the ROC curve (AUC) of $0.59(\mathrm{P}=0.03)$. The drift around the null hypothesis $(\mathrm{AUC}=0.5)$ where the variable cannot distinguish between two classes validates the conclusion that laser intensity values alone have marginal prospect to differentiate between birds and cave wall. Comparatively, the use of spectral and area properties in the classification process results in better detection capability with sensitivity and specificity values of $87 \%$ and $98 \%$ respectively (Fig. 7B). Despite a slight decrease in sensitivity as a result of shadow effect and low contrast, the strength of the area factor to detect non-bird objects neutralized the negative effect it could have had on the final accuracy (Table 4). Again, area under the ROC curve of 0.93 and p-value of $<0.0001$ was achieved at $95 \%$ confidence level. Since the P is by far smaller than 0.05 , it is valid to conclude that the area under the ROC curve is significantly different from 0.5 (the null hypothesis), confirming that our proposed method was able to distinguish between cave wall and birds with high accuracy.

\section{Reliability test results}

Reliability estimation requires analyzing the quantitative results of the individual trial to test for the homogeneity (null hypothesis). The initial task was to obtain the necessary variables for consistency test by examining the ROC curves of the six experiments concurrently. It can be seen that the ROC curves of the six experimental studies approach the upper left corner of the plot (Fig. 8); this is interpreted to mean a high overall accuracy similar to the result obtained previously for the 

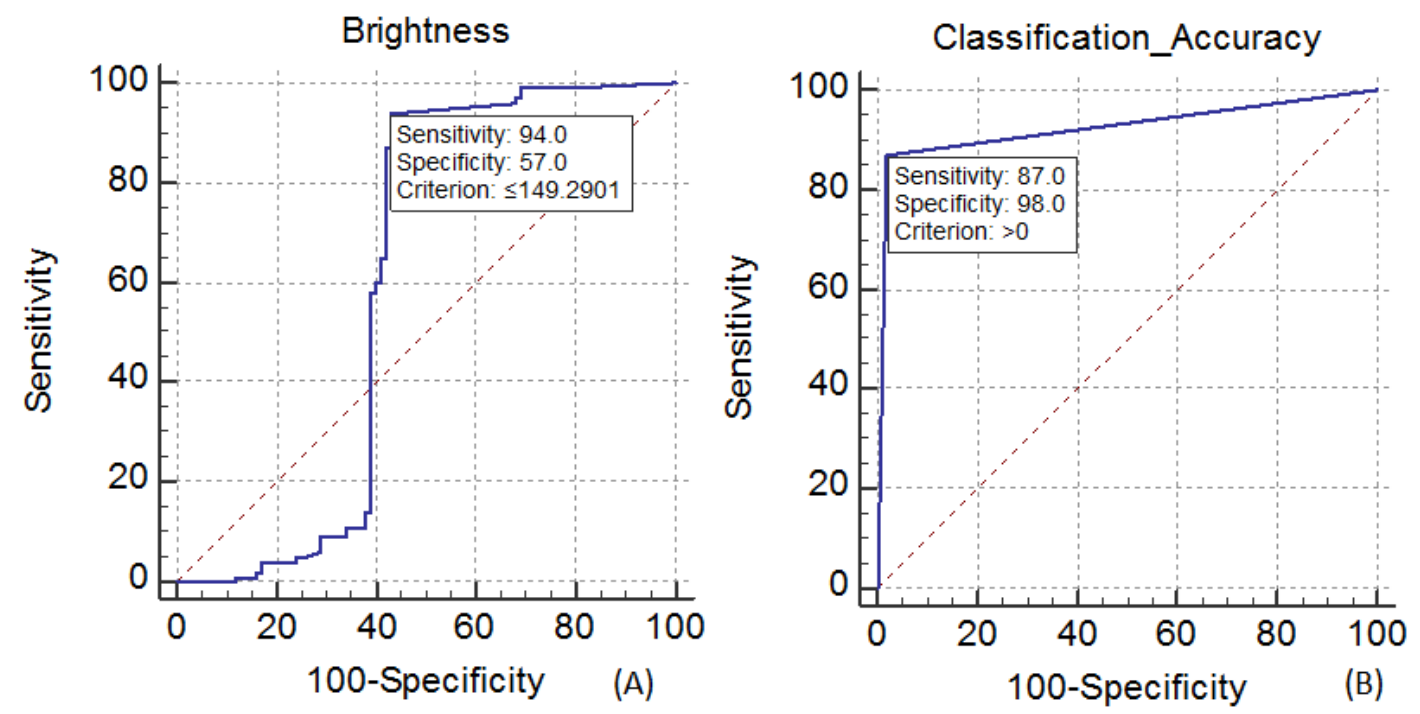

Fig. 7. ROC curves classification analysis with (a) brightness value, (b) area index, and (c) brightness and area indices.

Table 4. Classification accuracy: Area under the ROC curve with associated performance measures.

\begin{tabular}{|l|c|c|}
\cline { 2 - 3 } \multicolumn{1}{c|}{} & Brightness & $\begin{array}{c}\text { Brightness } \\
+\mathbf{a r e a}\end{array}$ \\
\hline Sensitivity & 94 & 87 \\
\hline Specificity & 57 & 98 \\
\hline Area under the ROC curve (AUC) & 0.59 & 0.93 \\
\hline Standard error & 0.046 & 0.018 \\
\hline 95\% Confidence interval & 0.527 to 0.667 & 0.879 to 0.957 \\
\hline Significance level P (Area $=0.5)$ & 0.0332 & $<0.0001$ \\
\hline
\end{tabular}

accuracy assessment. The calculated $\mathrm{P}$ values for each pair of the area under the compared ROC curves range between 0.093 and 1.0 , comparatively greater than the standard 5\% $(\mathrm{P}<0.05)$ cut-off. Meaning that the estimated area under the ROC curves at $95 \%$ exact Binomial confidence interval (Philip, 2011) do not exhibit a significant difference.

The test for statistical significance did established that a relationship exists; however, accepting with completely $100 \%$ assurance that a relationship exists between the variables without controlling the sources of error increases the chance of taking wrong

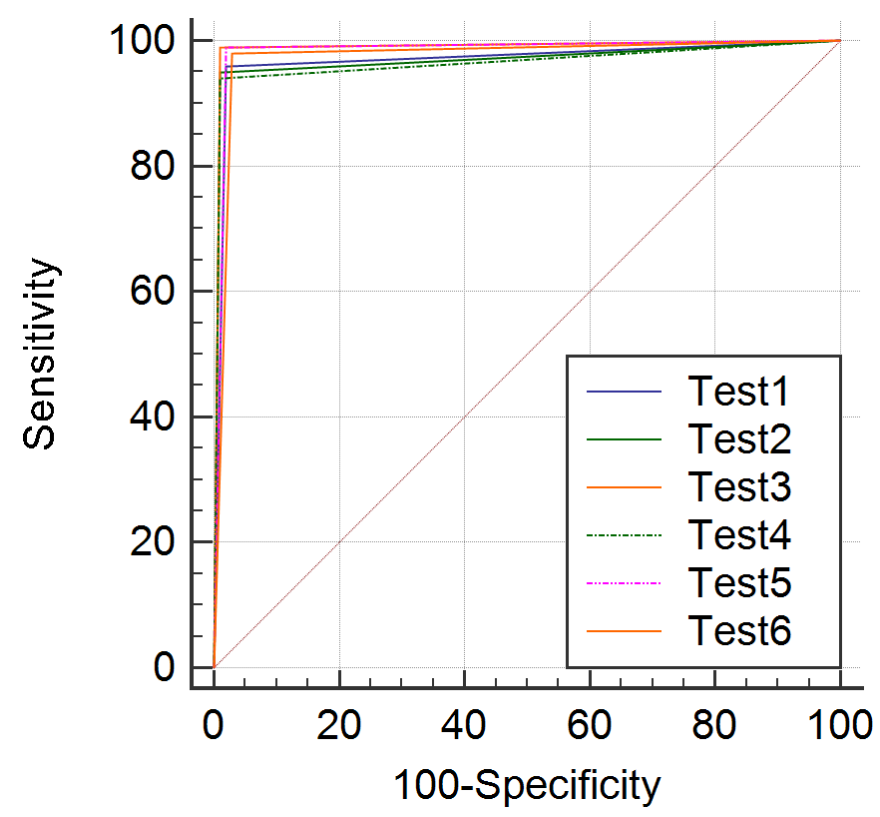

Fig. 8. Comparison of area under the ROC curves of the six experiments. conclusions if the probability of being wrong is not estimated. For instance, bias assumption in research design, research methodology, sampling error, human mistakes, etc. (Borenstein et al., 2009) may affect the reliability of the findings. So, analysis of the overall effects and tests for heterogeneity does not only provide statistical measure of significance, but also, the extent of the relationship.

Results of the six trials, with 95\% confidence interval, and the overall effect under the fixed and random effect models is shown in the forest plot (Fig. 9). In the figure, it can be seen that the all horizontal lines that define effect of the respective study at $95 \%$ confidence intervals overlap properly pictorially revealing agreement between the quantities. Similarly, the diamond marker symbolizes the summary effects. The position of the marker indicates the pooled effects size while the width which is the approximate $95 \%$ confidence interval given as

$$
\theta \pm 1.96 \sqrt{\left(1 / \sum w_{i}\right)}
$$

gives the precision of the estimation (i.e., 0.016). $w_{i}$ being the inverse of the standard error of the individual trial (Petrie et al., 2003; Borenstein et al., 2009; Philip 2011). Both the fixed and random effect models have equal effect size of 0.980 (Table $5)$. On the basis of the result of these two models, it suffices to state that the outcome of the six trials are compatible, that is there is no heterogeneity. Nevertheless, being compatible does not mean that the results are consistent.

The test of heterogeneity with the two prominent statistical tools, Cochran's Q and inconsistency $\mathrm{I}^{2}$ (Table 5), provide a measure and degree of reliability. The Q-test yields a p-value of 0.384, commonly interpreted as being non-significant based on the suggested threshold of $\mathrm{p}<0.1$ due to its low sensitivity to true heterogeneity (Higgins et al., 2003). The result implies that the null hypothesis of homogeneity is valid and therefore cannot be rejected, nonetheless, it does not provide evidence that there is no heterogeneity at all. So, the extent of the effect of heterogeneity was 


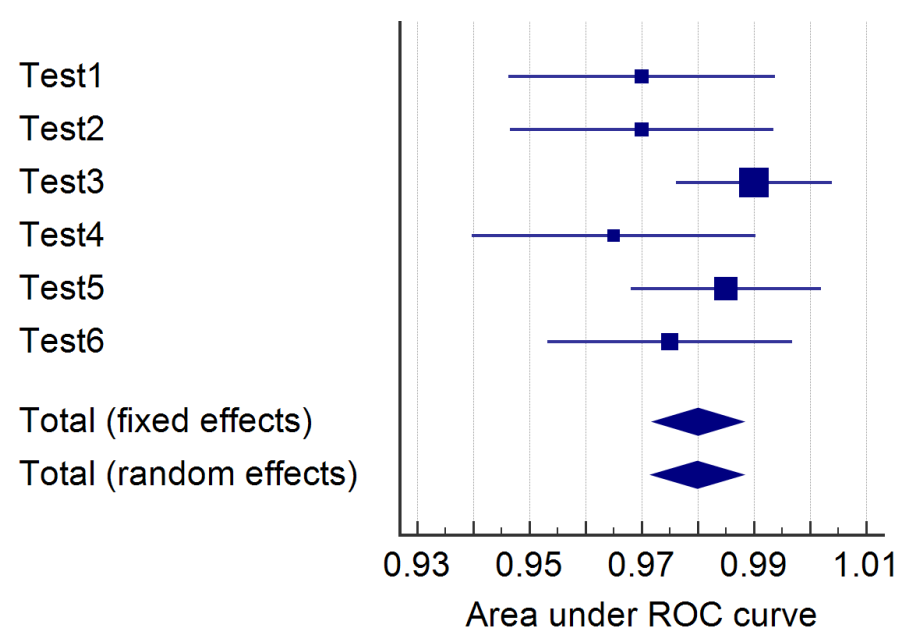

Fig. 9. Area under the ROC curve of the six experimental trials at $95 \%$ confidence interval and the overall effects. The horizontal lines shows the coverage of the confidence interval with square markers that vary in size according to the weights assigned.

Table 5. Estimated overall effects and test for heterogeneity. quantified using a measure of inconsistency. The value of $\mathrm{I}^{2}$ shows a minor degree of inconsistency $\left(\mathrm{I}^{2}=5.10 \%\right)$ among the trials that results from true heterogeneity. Practically, the result of the inconsistent test is also not significant enough too to reject the null hypothesis. Consequently, the summary of all statistical tests point to the same conclusion that the test of homogeneity is not significant and therefore the null hypothesis (that all the studies observe the same effects) can be accepted. Ultimately, it is valid to conclude that the method that produced consistent effects across the six experimental trials is reliable.

Following the reliability test, the detected nests in each scan scene were also counted. The results obtained are: 4,$143 ; 3,188 ; 3,881 ; 1,618 ; 3,526$; and 2,297 in that order for image one to six. In all, a total number of 25, 959 nests were counted from the seven images used to test this method. Fig. 10 presents the nests detected on the respective images.

\begin{tabular}{|c|c|c|c|c|c|}
\hline Study & ROC area & Standard error & $95 \% \mathrm{CI}$ & \multicolumn{2}{|c|}{ Test for heterogeneity } \\
\hline Test1 & 0.970 & 0.0121 & 0.946 to 0.994 & $\mathrm{Q}$ & 5.2687 \\
\hline Test2 & 0.970 & 0.0120 & 0.946 to 0.994 & $\mathrm{DF}$ & 5 \\
\hline Test3 & 0.990 & 0.00707 & 0.976 to 1.000 & Significance level & $\mathrm{P}=0.3840$ \\
\hline Test4 & 0.965 & 0.0129 & 0.940 to 0.990 & $\mathrm{I}^{2}$ (inconsistency) & $5.10 \%$ \\
\hline Test5 & 0.985 & 0.00863 & 0.968 to 1.000 & $95 \% \mathrm{CI}$ for $\mathrm{I}^{2}$ & 0.00 to 76.61 \\
\hline Test6 & 0.975 & 0.0111 & 0.953 to 0.997 & & \\
\hline Total (fixed effects) & 0.980 & 0.00404 & 0.972 to 0.988 & & \\
\hline Total (random effects) & 0.980 & 0.00412 & 0.972 to 0.988 & & \\
\hline
\end{tabular}

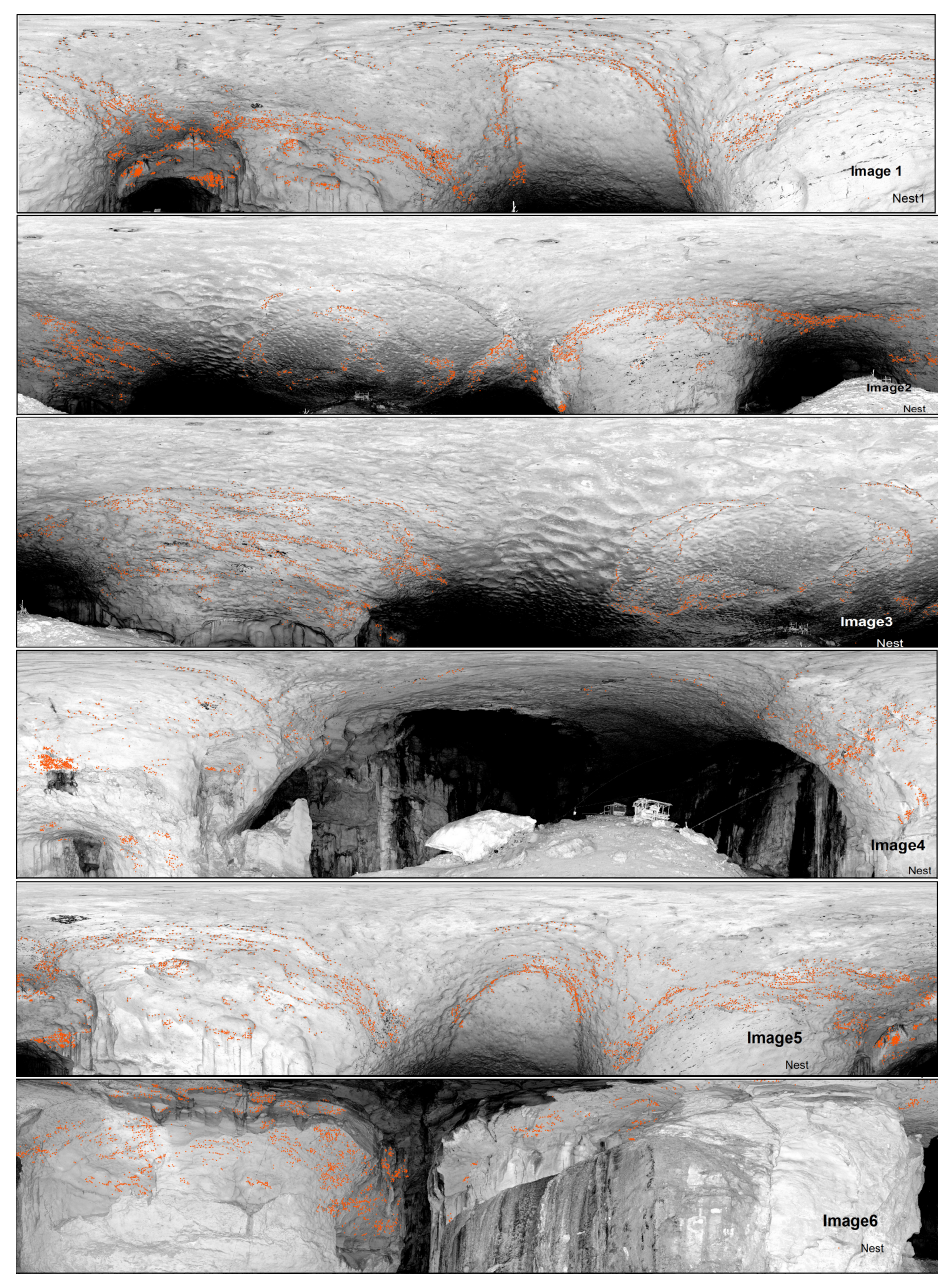

Fig. 10. Six images used for validating the method showing the detected bird-nests in red dots.

\section{CONCLUSIONS}

Processing large volumes of point clouds currently faces enormous challenges that limit the use of $x y z-$ point dataset for bird population inventory to quite very small areas. However, laser intensity images from high-resolution scanning offer potentially adequate feature characteristics to effectively extract information using remote sensing image analysis techniques. Our method demonstrates resourcefulness as an effective tool to suitably detect nests over large areas with high precision, and therefore expedites counting to the tune of tens of thousands of birds. The method can precisely detect nests in large number across wide areas for ecological studies, population census, and conservation management planning, but cannot be used to differentiate between species of birds. Contrary to the use of 3D point datasets for population surveys, this method is computationally efficient, timely, and may be useful in different caves for the same purpose.

\section{ACKNOWLEDGEMENTS}

This research is supported by Ministry of Higher Education, Malaysia research grant (FRGS/12014- STWN06/UPM//02/1) with vote number 5524502 and University Putra Malaysia research grant (GP- 1/2014/943200). Authors would like to thank Prof. Dr. Manfred Buchroithner for the joint terrestrial laser scanning data expedition funded by the National Geographic Society. We thank 
Professor Donald McFarlane of the Keck Science Center, Claremont Colleges (USA) for his valuable contribution to improving the research outcome, and not also forgetting the anonymous reviewers for their comments, suggestions and contribution. Our appreciation also goes to Dr. Keith Christenson for providing high-resolution photograph taken in the cave during the scanning expedition.

\section{REFERENCES}

Abdullah M.T., Paul I.V. \& Hall L., 2005 - A frightful stairway to cave bats in Borneo. Bat Conservation International, 23 (3): 11-13.

Abdullah M.T., Hall L.S., Tissen O.B., Tuuga A. \& Earl O.C., 2007 - The large bat caves of Malaysian Borneo. Bat Research News, 48 (3): 99-100.

Anders N.S., Seijmonsbergen A.C. \& Bouten W., 2011 - Segmentation optimization and stratified object-based analysis for semi-automated geomorphological mapping. Remote Sensing of Environment, 115 (12): 2976-2985. http://dx.doi.org/10.1016/j.rse.2011.05.007

Azmy S.N., Sah S.A.M., Shafie N.J., Ariffin A., Majid Z., Ismail M.N.A. \& Shamsir M.S., 2012 - Counting in the dark: non-intrusive laser scanning for population counting and identifying roosting bats. Scientific Reports, 2: 524. http://dx.doi.org/10.1038/srep00524

Besl P., \& McKay N., 1992 - A Method for Registration of 3-D Shapes. IEEE Transactions on Pattern Analysis and Machine Intelligence, 14 (2): 239-256.

http://dx.doi.org/10.1109/34.121791

Blaschke T. 2010 - Object based image analysis for remote sensing. ISPRS Journal of Photogrammetry and Remote Sensing, 65 (1): 2-16.

http://dx.doi.org/10.1016/j.isprsjprs.2009.06.004

Blaschke T., Feizizadeh B. \& Hölbling D., 2014 - Objectbased image analysis and digital terrain analysis for locating landslides in the Urmia Lake Basin, Iran. IEEE Journal of Selected Topics in Applied Earth Observations and Remote Sensing, 7 (12): 1-12. http://dx.doi.org/10.1109/JSTARS.2014.2350036

Borenstein M., Hedges L.V., Higgins J.P.T. \& Rothstein H. R., 2009 - Introduction to meta-analysis. John Wiley \& Sons, Ltd, West Sussex, 415 p.

http://dx.doi.org/10.1002/9780470743386

Chasen F.N., 1931 - Report on the Birds' Nest Cave and industry of British north Borneo with special reference to the Gomantong Caves. The Government Printing Office, Jesselton, North Borneo: 24 p.

Cheng G., Guo L., Zhao T., Han J., Li H. \& Fang, J. 2013 - Automatic landslide detection from remote-sensing imagery using a scene classification method based on BoVW and $p L S A$. International Journal of Remote Sensing, 34 (1): 45-59.

http://dx.doi.org/10.1080/01431161.2012.705443

Chou C.S., Ho C.Y. \& Huang C.I., 2009 - The optimum conditions for comminution of magnetic particles driven by a rotating magnetic field using the Taguchi method. Advanced Powder Technology, 20 (1): 55-61. http://dx.doi.org/10.1016/j.apt.2008.02.002

Danneels G., Pirard E. \& Havenith H.B., 2007 - Automatic landslide detection from remote sensing images using supervised classification methods. Geoscience and Remote Sensing Symposium, 2007. IGARSS 2007. IEEE International: 3014-3017.

http://dx.doi.org/10.1109/IGARSS.2007.4423479
eCognition (Version 9.0.1), 2014 - Trimble eCognition Developer User Guide. Munich, Germany, Trimble Germany GmbH.

Espindola G.M., Camara G., Reis I.A., Bins L.S. \& Monteiro A.M., 2006 - Parameter selection for regiongrowing image segmentation algorithms using spatial autocorrelation. International Journal of Remote Sensing, 27 (14): 3035-3040.

http://dx.doi.org/10.1080/01431160600617194

Flach P., Hernández-Orallo J. \& Ferri C., 2011 A coherent interpretation of auc as a measure of aggregated classification performance. In: Proceedings of the $28^{\text {th }}$ International Conference on Machine Learning (ICML11): 657-664.

http://dx.doi.org/10.1145/347090.347126

Gao Y., Kerle N., Mas J., Navarrete A. \& Niemeyer I., 2011 - Optimized image segmentation and its effect on classification accuracy. International Journal of Remote Sensing, 32 (13): 3747-3762.

http://dx.doi.org/10.1080/01431161003777189

Haddad N.A., 2011 - From ground surveying to $3 D$ laser scanner: A review of techniques used for spatial documentation of historic sites. Journal of King Saud University - Engineering Sciences, 23 (2): 109-118. http://dx.doi.org/10.1016/j.jksues.2011.03.001

Hanley J.A. \& McNeil B.J., 1982 - The meaning and use of the area under a receiver operating characteristic (ROC) curve. Radiology, 143 (1): 29-36.

http://dx.doi.org/10.1148/radiology.143.1.7063747

Higgins J.P.T., Thompson S.G., Deeks J.J. \& Altman D.G., 2003 - Measuring inconsistency in meta-analyses. British Medical Journal, 327 (7414): 557-560. http://dx.doi.org/10.1136/bmj.327.7414.557

Idrees M.O. \& Pradhan B., 2016 - A decade of modern cave surveying with terrestrial laser scanning: $A$ review of sesors, method and application development. International Journal of Speleology, 45 (1): 71-88. http://dx.doi.org/10.5038/1827-806X.45.1.1923

Kingston T., 2010 - Research priorities for bat conservation in Southeast Asia: a consensus approach. Biodiversity and Conservation, 19 (2): 471-484. http://dx.doi.org/10.1007/s 10531-008-9458-5

Kurtz C., Stumpf A., Malet J.P., Gançarski P., Puissant A. \& Passat N., 2014 Hierarchical extraction of landslides from multiresolution remotely sensed optical images. ISPRS Journal of Photogrammetry and Remote Sensing, 87: 122-136.

http://dx.doi.org/10.1016/j.isprsjprs.2013.11.003

Lahousse T., Chang K.T. \& Lin Y.H., 2011 - Landslide mapping with multi-scale object-based image analysis-a case study in the Baichi watershed, Taiwan. Natural Hazards and Earth System Sciences, 11 (10): 2715-2726. http://dx.doi.org/10.5194/nhess-11-2715-2011

Lundberg J. \& McFarlane D.A., 2012 - Post-speleogenetic biogenic modification of Gomantong Caves, Sabah, Borneo. Geomorphology, 157-158: 153-168. http://dx.doi.org/10.1016/j.geomorph.2011.04.043

Martha T.R., Kerle N., Van Westen C.J., Jetten V. \& Kumar K.V., 2011 - Segment optimization and data-driven thresholding for knowledge-based landslide detection by object-based image analysis. IEEE Transactions on Geoscience and Remote Sensing, 49 (12): 4928-4943. http://dx.doi.org/10.1109/TGRS.2011.2151866

McFarlane D.A., Buchroithner M., Lundberg J., Petters C., Roberts W. \& Van Rentergem G., 2013 - Integrated three-dimensional laser scanning and autonomous drone surface-photogrammetry at Gomantong Caves, Sabah, Malaysia. In: Proceedings of the 16th International Congress of Speleology, Brno, 317-319. 
McFarlane D., Roberts W., Buchroithner M., Van Rentergem G., Lundberg J. \& Hautz S., 2015 Terrestrial LiDAR-based automated counting of swiftlet nests in the caves of Gomantong, Sabah, Borneo. International Journal of Speleology, 44 (2): 55-60. http://dx.doi.org/10.5038/1827-806X.40.1.2

Medcalc (Version 16), 2016 - MedCalc statistics for biomedical research software manual. Www.medcalc. org. Ostend, Belgium: MedCalc Software bvba.

Metz C.E., 1978 - Basic principles of ROC analysis. Seminars in Nuclear Medicine, 8 (4): 283-298. http://dx.doi.org/10.1016/S0001-2998(78)80014-2

Minitab (Version 17.3.0), 2016 - Getting Started with Minitab 17. Minitab Inc. Pennsylvania, USA, Minitab Inc.

Moosavi V., Talebi A. \& Shirmohammadi B., 2014 Producing a landslide inventory map using pixel-based and object-oriented approaches optimized by Taguchi method. Geomorphology, 204, 646-656. http://dx.doi.org/10.1016/j.geomorph.2013.09.012

Petrie A., Bulman J.S. \& Osborn J.F., 2003 - Further statistics in dentistry Part 8: Systematic reviews and meta-analyses. British Dental Journal, 194 (2): 73-78. http://dx.doi.org/10.1038/sj.bdj.4809877

Philip M., 2011 - Understanding binomial confidence Intervals. Retrieved July 13, 2016, from http://www. sigmazone.com/binomial_confidence_interval.htm

Powers D.M.W., 2011 - Evaluation: from precision, recall and F-measure to ROC, informedness, markedness and correlation. Journal of Machine Learning Technologies, 2 (1): 37-63.
Pradhan B., Jebur M.N., Zulhaidi H., Shafri M. \& Tehrany M.S., 2015 - Data fusion technique using wavelet transform and Taguchi methods for automatic landslide detection from airborne laser scanning data and Quickbird satellite imagery. IEEE Transactions on Geoscience and Remote Sensing, 54 (3): 1-13. http://dx.doi.org/ 10.1109/TGRS.2015.2484325

Price L., 2007 - Gomantong bat caves awash in guano. The Brunei Times News, pp. 3-5. Brunei. Retrieved from http://www.bt.com.bn.

Price L., 2014 - Species diversity and food-web complexity in the caves of Malaysia. Ambient Science, 1 (2), 1-8. http://dx.doi.org/10.21276/ambi.2014.01.2.ga01

Rao R.S., Kumar C.G., Prakasham R.S. \& Hobbs P.J., 2008 - The Taguchi methodology as a statistical tool for biotechnological applications: A critical appraisal. Biotechnology Journal, 3 (4): 510-523.

http://dx.doi.org/10.1002/biot.200700201

Remondino F, 2003 - From point cloud to surface: the modeling and visualization problem. International Archives of Photogrammetry, Remote Sensing and Spatial Information Sciences, 34 (5): W10.

Thaduri A., Verma A.K., Gopika V. \& Kumar U., 2013 Reliability prediction of constant fraction discriminator using modified PoF Approach. In: Relaibility and Maintainability Symposium (RAMS), 2013 Proceedings. http://dx.doi.org/10.1109/RAMS.2013.6517746

Tumuhairwe S., 2011 - Evaluation of the transferability of a genetic algorithm for object oriented landslide mapping and pattern analysis for the 2010 Haiti earthquake. Unpublished MSc. Thesis, University of Twente, $82 \mathrm{p}$. 